\title{
Spatial-temporal changes of regional sustainability: an empirical study in Taiwan
}

\author{
Y.-T. Hung ${ }^{1} \&$ K.-W. Tsou ${ }^{2}$ \\ ${ }^{1}$ Department of Recreation and Health-care Management, \\ Chia Nan University of Pharmacy and Science, Taiwan, Republic of \\ China \\ ${ }^{2}$ Department of Urban Planning, National Cheng-Kung University, \\ Taiwan, Republic of China
}

\begin{abstract}
Under trends of globalization, reforms of economic development environment have become the most important national strategy for enhancing competitiveness in developing countries. However, there are debates as to whether these reformed strategies have considerable impacts on regional sustainability. In order to assess the impacts on regional sustainability, this paper presents a cohesive procedure to analyze spatial-temporal changes of regional sustainability and a dimension-based conceptual framework of an indicators system for measuring regional sustainability. Based on seven key selected criteria and a conceptual framework of three dimensions that are widely perceived to be the major factors in Taiwan sustainability, 27 operational measuring indicators are identified. In the proposed analytic procedure, GIS is first used to manage and display the spatial-temporal database in Taiwan. Secondly, factor analysis is used to highlight the underlying multidimensionality and structure of relationships among the regional sustainability indicators for all municipalities in Taiwan. Cluster analysis is also used to simply explore the spatial-temporal changes that emerge from the analysis. In the empirical study, we find nine common sustainability factors and five heterogeneous spatial clusters. Results from of the GIS-based multivariate statistics will be discussed as well as concluded in the final section.
\end{abstract}

Keywords: regional sustainability, spatial statistics, GIS. 


\section{Introduction}

In the last decade, there has been a growing recognition amongst planners and decision-makers in developing countries, which are facing considerable pressure of global competition. At the same time, reforms of economic development environment usually have become important national strategies for enhancing competitiveness in the global economy. Moreover, the national economic strategies may also have considerable impacts on the sustainable development at the local, regional and national levels. Consequentially, a spatial-temporal analysis of regional sustainability changes is necessary to support informed and valid responses in the debate. The assessment of regional sustainability changes throughout country's spatial system could provide valuable information for reformulating development strategies and support to achieve integration between environmental protection and economic development. To date, most of the empirical studies regarding regional sustainability have focused their analysis on the region itself and are aspatial. However, these individual aspatial approaches yield little insight into the detailed spatial distribution pattern of regional/local sustainability and cannot provide more sufficient planning information on the various responses of different regions and municipalities to environment fluctuation occurring over space.

With the above statements, three major issues are addressed in the paper: (1) What multidimensional indictors of regional sustainability should be selected to aid the spatial-temporal comparative analysis? (2) How can spatial-temporal changes of regional sustainability be analyzed and assessed? (3) What have changed, in the last decade, the regional sustainability of developing countries? For attempting to answer these questions, this paper presents a cohesive procedure (Fig. 1) to analyze spatial-temporal changes of regional sustainability and a dimension-based conceptual framework of indicators system for measuring regional sustainability. The procedure as we proposed that enables spatialtemporal comparisons of regional sustainability at municipal scale.

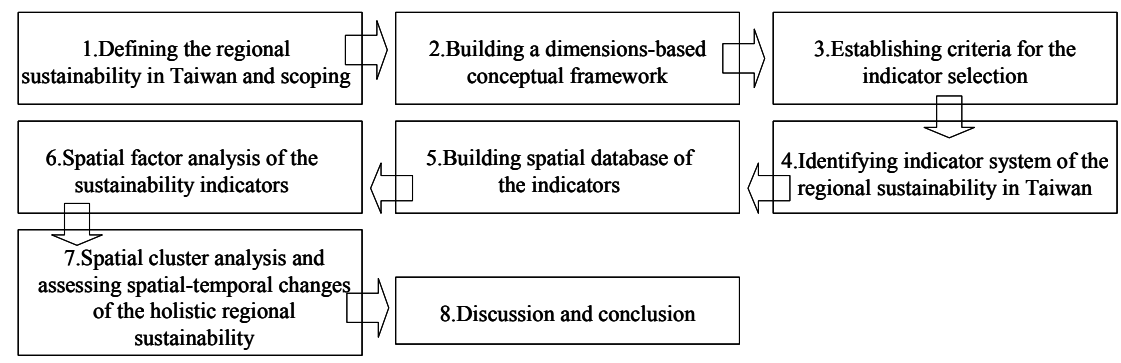

Figure 1: A proposed analytic procedure of regional sustainability.

Taiwan was chosen to test this conceptual framework and analytic procedure for three main reasons: (1) Diversity of natural and human landscape is very rich. (2) Because Taiwan is an urbanized island country, it has specific importance in sustainability system and could be observed independently. (3) Taiwan is one of 
the "Four Little Dragon", which had implemented many important strategies to overcome the challenges of global competition and economic redevelopment in the last decade (1995-2004). Meanwhile, the strategies have been argued that have seriously influenced the spatial development of regional sustainability.

\section{Regional sustainability and a conceptual framework of indicators}

The increasing role of region in sustainability stems from an understanding that the spatial effects of national development plans are not uniform, may be addressed more effectively at the regional levels. For example, the Asian Development Bank study on sustainable development had concluded that plans at the regional level provide a potentially powerful bridge between national plans and local plans and projects [1].

In the last two decades, particularly since the report of the World Commission on Environment and Development, entitled "Our Common Future" [2], sustainability and related term sustainable development have become catchwords in the regional and urban planning. Efforts to assess and improve sustainability have been a part of the planning profession. There are different understandings and definitions, [3-5] showed they are significant but vague. For example, Robinson et al. [5] define sustainability as "the persistence over an apparently indefinite future of certain necessary and desired characteristics of the socio-political system and its natural environment." Because no universally accepted definition exists, we have to set out our working understanding of regional sustainability and conceptual framework. A conceptual framework for indicators is necessary to guide the creators of indicator sets [6]. In general, there are six general frameworks that can be used for developing sustainability indicators, including dimension-based (domain-based) frameworks, goal-based frameworks, sectoral frameworks, issue frameworks, causal frameworks, and combination frameworks. Meanwhile, the dimension-based frameworks are most effective for accentuating the holistic aspect of sustainability [7]. In the paper, in accordance with the framework used by the National Council for Sustainable Development (NCSD) in Taiwan in their national sustainable development indicators, three core dimensions of a dimension-based conceptual framework have been identified, i.e. social life, economic production and environmental ecology. Using the proposed conceptual framework, it could create a set of indicators based on a number of criteria.

In recent years, although many indicators have been used in sustainability assessments [8], most of indicators are either based on smaller level (e.g. community level) or larger level (e.g. national level). However, indicators at national level may mask problems in regions with highly unsustainable conditions [9]. In contrast, indicators at community level usually neglect the critical regional level interaction among rural area, suburban and urban [10]. One has to define and select appropriate sustainability indicators for the study [11]. In addition, highly heterogeneous nature of local circumstance has thus led to different interpretations of regional sustainability. As a result, the indicators 
should be rebuilt to suit different regional environment. Indicators for this study were redrawn from an extensive literature review of material pertaining to the characteristics of regional sustainability. Besides, indicators were also modified through many less formal discussions with other experts.

Based on an extensive literature review (e.g. [9]), and series of discussions, the following seven key criteria were established for the indicator selection to ensure their viability: (1) Holistic. The indicators should be incorporated as an integral and on-going framework. (2) Computable. The indicators should be measurable with quantified technology (3) Unambiguous. The indicators should be unambiguous for providing clear information. (4) Scientific. The indicators should be scientifically valid for measuring sustainability. (5) Comparable. The indicators should be comparable for enabling comparison across inter/intra regions. (6) Sensitive. The indicators should be sensitive to changes. (7) Available. The data of indicators should be available from existing sources. These criteria could provide a series of useful guidelines, which results in an indicator system that meets the needs of the empirical study in Taiwan.

\section{Empirical study area}

Taiwan has an area of $36,006 \mathrm{~km}^{2}$. According to the regional plans, Taiwan is divided into four regions (North, Central, South and East, Fig. 2). At mid-2003, its population stood at 22.5 million. Taiwan is one of the most densely populated areas in the world $\left(625 \mathrm{capita} / \mathrm{km}^{2}\right)$. Main terrain type is mountain (above $60 \%$ ) and is not richly endowed by nature. Taiwan is a developing country, although its economy has entered a more-mature stage in recent years. To meet the needs of enhancing national competitiveness in the global economics, most national spatial redevelopment plans have focused on accelerating economic development. During the last decade, its main industry has shifted from labourintensive to technology-intensive production. High-tech industries have dominated the manufacturing sector (approximate 36\% of total manufacturing value). However, many research articles had implied that regional sustainability in Taiwan might be degraded for implementing these plans. Currently, Taiwan has come to the sustainable development crossroads. Policymakers and planners are now aware that they have the responsibility and the confidence to overcome the difficult challenges for promoting greater sustainability. At policy level, Taiwan chooses the path of sustainable development with the year 2003 as the starting year. The NCSD has developed a set of national-level sustainable development indicators (SDIs) for use in Taiwan. However, they are only suitable for assessing national level sustainability.

\section{Methods}

To analyze the spatial-temporal change of regional sustainability in developing countries is a difficult task. Municipality-based regional systems comprise a complex data problem that is not easy to analyze. In addition, empirical study of spatial-temporal change requires the numerous data that are disaggregated by 
space and time. In the last decade, GIS has gained popularity as a powerful tool for the management of spatial-temporal database. GIS is an information system that is used to input, store, retrieve, manipulate, analyze and display geospatial or descriptive data. Meanwhile, GIS-based technologies (e.g. spatial multivariable statistics) can offer an efficient and effective way to solve the problems involved in the development of spatial-temporal analysis.

While collecting the three sets of individual indicators, the indicator system brings a large amount of disparate information together [7, 10]. The underlying interaction and structure among the indicators should be reformulated by factor analysis. Factor analysis has been widely used for exploring spatial patterns [12]. Typically, the technology of factor analysis specially concerns with interrelationships among a set of variables. The result of factor analysis can explain the total covariance of a set of variance in terms of far smaller number of underlying factors.

An agglomerative hierarchical clustering analysis was applied to identify clusters of the municipalities. It is computationally more intensive than other clustering method and is easier to interpret [13]. The analytic method can group the municipalities into several clusters with homogeneity among changed degrees of sustainability within each cluster, and heterogeneity between clusters.

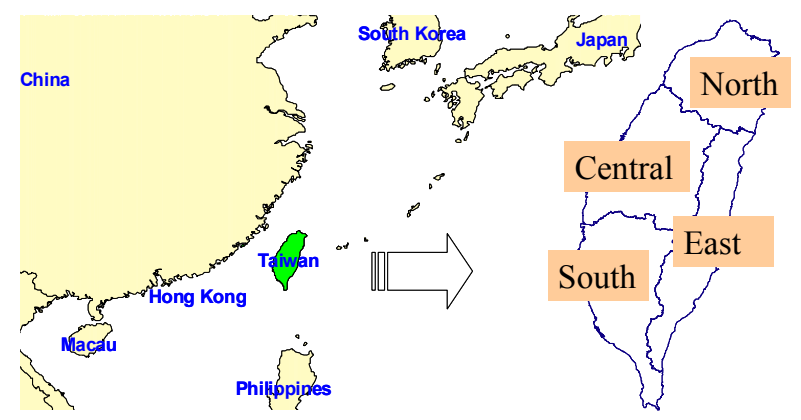

Figure 2: $\quad$ Location of Taiwan and regional division.

\section{Indicator system}

We invited 10 related experts and scholars to establish a less formal discussion group for selecting sustainability indicators that can be used in municipalitybased comparison. Meanwhile, the selection of indicators is also guided by the above criteria. 27 meaningful and representative indicators for sustainability measurement were finally selected (Table 1). The formulation of the indicators is consistent with the three core dimensions of the conceptual framework which has been stated above. Because partial related databases are insufficient, several important indicators (such as biodiversity) are not yet adapted in the initial indicator system. In according to the schedule of national development plans in Taiwan, temporal analysis would focus on the changes between two time points of 1995 and 2004. 
Table 1: $\quad$ Indicator system of regional sustainability in Taiwan.

\begin{tabular}{|c|c|c|}
\hline Dimension & Sustainability indicator & Operational definition \\
\hline \multirow[t]{9}{*}{ Social life } & S1: Final expenditure of government & Final expenditure /a person \\
\hline & S2: Public \& social services groups & $\begin{array}{l}\text { Groups of medical care \& social service\& } \\
\text { charity }\end{array}$ \\
\hline & S3: Mobility & No. of (Move in + move out)/all population \\
\hline & S4: Dependency rate & $\begin{array}{l}\text { (Population above } 65 \text { years old +Population } \\
\text { under } 14 \text { years old) / population between } 15 \text { and } \\
64\end{array}$ \\
\hline & S5: Medical treatment & Per capita physicians \\
\hline & S6: Dwelling level & Housing area / a household \\
\hline & S7: Automobile usage & Per capita automobiles \\
\hline & S8: Resource recycling & Amount of recycle resource / all garbage \\
\hline & S9: Proportion of unused land & Area of unused land / total area of land \\
\hline \multirow[t]{9}{*}{$\begin{array}{l}\text { Environmen } \\
\text { al ecology }\end{array}$} & \begin{tabular}{|l|} 
E1: Government expenditure on \\
environment protection
\end{tabular} & Final expenditure /a person \\
\hline & E2: Atmospheric quality & $\%$ of measurement days which PSI $<50$ \\
\hline & E3: Daily water consumption & Per capita daily water consumption \\
\hline & E4: Electricity consumption & KWH per capita \\
\hline & E5: Daily solid waste disposal & Amount of wastes / 365 days \\
\hline & E6: Agricultural production area & Area of Agricultural production \\
\hline & E7: Green land and park area & Green land and park area/current population \\
\hline & $\begin{array}{l}\text { E8: Building construction in urban } \\
\text { planned districts }\end{array}$ & $\begin{array}{l}\text { Area of building construction of housing and } \\
\text { commerce in urban planned districts }\end{array}$ \\
\hline & $\begin{array}{c}\text { E9: Interior to edge ration of building } \\
\text { in non-urban planned districts }\end{array}$ & $\begin{array}{l}\Sigma(\mathrm{P} / \mathrm{A}) / \mathrm{N} \text { of buildings in non-urban planned } \\
\text { districts }\end{array}$ \\
\hline \multirow[t]{9}{*}{$\begin{array}{l}\text { Economic } \\
\text { production }\end{array}$} & $\begin{array}{l}\text { P1: Labour force of manufacturing } \\
\text { industry }\end{array}$ & $\begin{array}{l}\text { Labour force of manufacturing industry / all } \\
\text { population }\end{array}$ \\
\hline & \begin{tabular}{|l|} 
P2: Output value of manufacturing \\
industry land use
\end{tabular} & $\begin{array}{l}\text { Revenues of manufacturing industry / area used } \\
\text { by manufacturing industry }\end{array}$ \\
\hline & $\begin{array}{l}\text { P3: Labour force of commercial } \\
\text { business }\end{array}$ & $\begin{array}{l}\text { Labour force of commercial business / all } \\
\text { population }\end{array}$ \\
\hline & \begin{tabular}{|l|} 
P4: Output value of commercial \\
business land use
\end{tabular} & $\begin{array}{l}\text { Revenues of commercial business / area used by } \\
\text { commercial business }\end{array}$ \\
\hline & P5: Scale of agriculture & No. of workers in agriculture \\
\hline & P6: Scale of manufacturing industry & No. of workers in manufacturing industry \\
\hline & P7: Scale of commercial business & No. of workers in commercial business \\
\hline & \begin{tabular}{|l|} 
P8: Population with educational level \\
beyond junior college
\end{tabular} & $\begin{array}{l}\text { Population with educational level beyond junior } \\
\text { college including vocational school }\end{array}$ \\
\hline & P9: Average family income & Average family income \\
\hline
\end{tabular}

\section{Spatial-temporal changes of the regional sustainability factors}

The spatial-temporal changes of the regional sustainability factors during 19952004 can be portrayed by factor analysis, a class of multivariate statistical methods whose primary purpose is to define the underlying structure in a data matrix. The analysis can first identify the separate dimensions of the structure and then determine the extent to which the variance contributed by each variable is explained by each dimension. Once these dimensions and the explanation of each variable are determined, the two primary uses for factor analysis summarization and data reduction - can be achieved. In summarizing the data, 
factor analysis derives underlying dimensions that, when interpreted and understood, describe the data in a much smaller number of factors than did the original individual variables. Using the principal components and the varimax rotation methods, the analysis extracts 9 factors with eigenvalues greater than 1 in this study. The total variance that could be explained by these factors is $57.67 \%$. The nine dimensions with their respective factor loadings (F.L.) are shown as Table 2.

\subsection{Factor 1: manufacturing industry}

Factor 1 contains two indicators: labour force of manufacturing industry, and output value of land use of manufacturing industry. These indicators have positive values and it means that the sample district is getting mature in a manufacturing-oriented area.

\subsection{Factor 2: usage of non-renewable resource}

Factor 2 includes electricity consumption, and automobile usage. This dimension shows gradual increases in resources consumption and discharge production during 1995-2004 in districts composing this factor. The increasing usage of non-renewable resources is detrimental to sustainable development.

\subsection{Factor 3: decay agriculture}

Scale of agriculture and agricultural production area are included in the factor 3, with negative F.L. for both indictors. The decreases in both indicators represent that these districts have become decayed in agricultural because scale of agriculture and agricultural production area have declined.

\subsection{Factor 4: upgrading the quality of public service}

Factor 4 contains two indicators: Final expenditure of government and government expenditure on environment protection. All the indicator values are positive. It reveals that the public service and quality of environment is upgrading in the sample district in the last decade.

\subsection{Factor 5: resources of public service}

Medical treatment and population with educational level beyond junior college are included in the factor 5, with negative F.L. for both indictors. The decreases in both the medical treatment and the education level are decreasing imply that these districts have become barren area in resources of public service.

\subsection{Factor 6: urban sprawl}

Factor 6 has two indicators: mobility and interior to edge ration in non-urban planned districts. Since F.L. are positive, it shows people have moved into suburbs, and results in urban sprawl. Moreover, interior to edge ration revels that 
these districts have become fragmentary area, it is detrimental to sustainable development.

\subsection{Factor 7: urbanization}

Factor 7 has three indicators: labour force of commercial business, output value of land use of commercial business, and building construction in urban planned districts. Since F.L. are positive, it shows commercial business is flourishing, and the area of housing and commerce is increasing. In other words, the degree of urbanization is getting higher in the sample district.

\subsection{Factor 8: degenerate in environmental quality}

Two indicators with negative F.L. - public and social services groups, and atmospheric quality make up this factor. That is, enthusiasm of residents to participate local affairs is reducing, meanwhile, the environmental quality is going down, and it is detrimental to sustainable development.

Table 2: $\quad$ Factor loadings of 27 sustainability indicators in the eight factors.

\begin{tabular}{|c|c|c|c|c|c|c|c|c|c|}
\hline Variable & Factor 1 & Factor 2 & Factor 3 & Factor 4 & Ctor & w & Factor & Stor & \\
\hline P1 & 0.9189 & 0.0164 & -0.0225 & 0.0501 & \begin{tabular}{|l|}
-0.0291 \\
\end{tabular} & -0.0520 & 0.2012 & -0.0002 & \begin{tabular}{|l|l}
0.0349 \\
\end{tabular} \\
\hline P2 & 217 & 6670 & 166 & & 412 & & 2011 & & \\
\hline P3 & 475 & 0.0051 & 0.0281 & -0.0150 & 0.0150 & & .8226 & .0043 & \\
\hline P4 & 2448 & 0.0543 & 0.0104 & -0.0059 & 0.0954 & 0.0878 & 0.7781 & 0.0760 & \\
\hline P5 & 599 & -0.1630 & 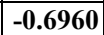 & \begin{tabular}{|l|}
-0.2422 \\
\end{tabular} & -0.0053 & -0.1294 & & 520 & \\
\hline P6 & -0.0461 & 0.1256 & 0.0021 & 0.0973 & 0.0186 & -0.0150 & -0. & 028 & -0. \\
\hline P7 & -0.1418 & 0.0294 & -0.0326 & -0.0500 & -0.0258 & -0.0993 & & & \\
\hline P8 & & .0917 & & & & & & & \\
\hline P9 & & & & & & & & & \\
\hline S1 & & & & & & & & & \\
\hline S2 & & & & & & & & & \\
\hline $\mathrm{S} 3$ & & & & & & & & & \\
\hline S4 & & & & & & & & & \\
\hline S5 & & & & & & & & & \\
\hline 56 & & & & & & & & & \\
\hline S7 & & & & & & & & & \\
\hline & & & & & & & & & \\
\hline S9 & & & & & & & & & \\
\hline E1 & & & & & & & & & \\
\hline E2 & & & & & & & & & \\
\hline E3 & & & & & & & & & \\
\hline $\mathrm{E} 4$ & & & & & & & & & \\
\hline E. & & & & & & & & & \\
\hline E6 & & & & & & & & & \\
\hline E7 & & & & & & & & & \\
\hline $\mathrm{E} 8$ & & & & & & & & & \\
\hline- & & 43 & 36 & 23 & 02 & 56 & 0.0019 & 0.0281 & -0.0361 \\
\hline & & & & & & & & & 1.3155 \\
\hline rp.Totl & 0849 & 0.0913 & 0.0542 & 0.0586 & 0.0506 & 0.0510 & 0.0773 & 0.0496 & 0.0487 \\
\hline
\end{tabular}




\subsection{Factor 9: degenerate in manufacturing industry and commercial business}

Factor 9 contains scale of manufacturing industry and scale of commercial business. These indicators have negative value. This means that the sample district is getting decline in manufacturing industry and commercial business, the industries is moving out or close down, in other words, the district is facing the difficulty in manufacturing industry and commercial business.

\section{Spatial-temporal changes of the holistic regional sustainability}

In order to fully reflect the sustainability of the regional condition changes during 1995-2004, it was necessary to embark on a complex process of information gathering. The complexity of the data made it difficult to understand the spatial meaning of the data. Hence, cluster analysis was used to assist the research and clarify the meaning of the data. The brief summary of spatial structure is shown as Fig. 2. Across the 350 municipalities of Taiwan, the research used Semi-Partial R-Squared indicator method [12] to identify five clearly defined clusters (Fig. 3). The characteristics and analysis of the clusters are presented below (Table 3 ).

\subsection{Cluster 1}

This group includes 122 municipalities, which are mainly located in the northern, central and southern region. Table 3 shows that the characteristic of this cluster is unapparent. Only factor 2 has little negative effect. These 122 municipalities are optimistic in sustainable development due to good control of usage of nonrenewable resource.

\subsection{Cluster 2}

11 municipalities are spread over five regions of Taiwan. The main characteristics of this cluster are obvious growing in agriculture, manufacturing industry and raising quality of public service rapidly.

\subsection{Cluster 3}

This includes 161 municipalities and is the biggest cluster of all. It is mainly located in the central and southern regions. There is no particular character in this cluster that is no apparent changes in the last decade.

\subsection{Cluster 4}

This area includes 43 municipalities which are mainly distributed in northern, central and eastern regions that near the seaside coastland. Factor 5 is the significant factor. This region apparently belongs to sustainable development 
area due to notable improvement of its resources of medical treatment and education.

\subsection{Cluster 5}

This area includes 13 municipalities which are gathered up at the mountain area in southeaster region and northeaster region. Factor 1 and 7 are the significant factors. Table 2 reveals that the manufacturing industry has been expanded substantially, and the degree of urbanization is getting higher in this cluster. These 13 municipalities belong to emerging area, and might have negative effects on sustainable development. Nevertheless, active management planning will be needed in the future.

Table 3: $\quad$ Each factor's average scores of the five clusters.

\begin{tabular}{|l|r|r|r|r|r|r|r|c|c|}
\hline Factor|Cluster & Factor1 & Factor2 & Factor3 & Factor4 & Factor5 & Factor6 & Factor7 & Factor8 & $\begin{array}{c}\text { No. of } \\
\text { municipality }\end{array}$ \\
\hline Cluster 1 & -0.0561 & $\mathbf{- 0 . 8 9 9 3}$ & 0.1657 & -0.0705 & -0.0432 & 0.2383 & -0.2370 & -0.0746 & 122 \\
\hline Cluster 2 & $\mathbf{1 . 9 9 4 2}$ & -0.3370 & $-\mathbf{1 . 8 9 3 3}$ & $\mathbf{3 . 0 7 4 2}$ & 0.2789 & -0.4016 & -0.7241 & -0.2661 & 11 \\
\hline Cluster 3 & -0.2257 & 0.5337 & 0.0334 & -0.0278 & 0.4691 & -0.0884 & -0.0721 & 0.0271 & 161 \\
\hline Cluster 4 & -0.0162 & 0.6356 & -0.1401 & -0.4333 & $\mathbf{- 1 . 7 6 7 8}$ & -0.2622 & -0.1906 & 0.1533 & 43 \\
\hline Cluster 5 & $\mathbf{1 . 6 8 7 5}$ & 0.0117 & 0.0964 & -0.1620 & 0.2067 & 0.0650 & $\mathbf{4 . 3 6 0 3}$ & 0.0826 & 13 \\
\hline
\end{tabular}

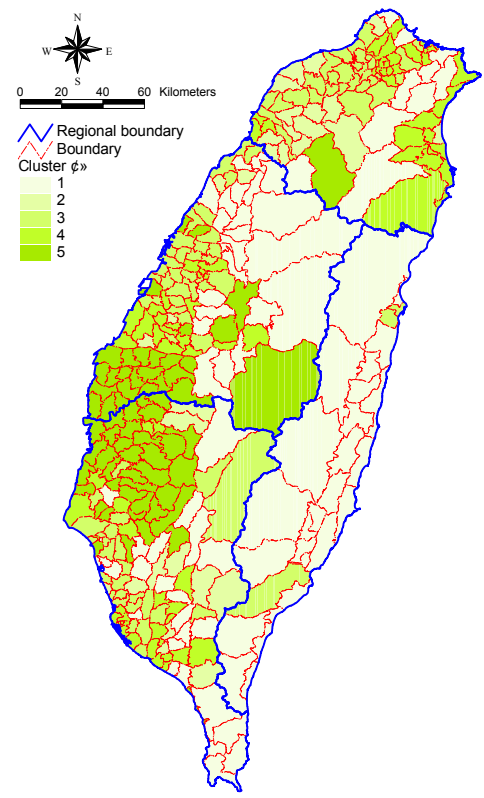

Figure 3: Heterogeneous spatial cluster in Taiwan. 


\section{Discussion and conclusion}

In last decade, the national economic strategies of Taiwan have a highly heterogeneous impact on the regional and local sustainability through its influence on spatial restructure and infrastructure. In this study spatial pattern of the change has been clearly identified. The result of clustering analysis has revealed distinct differences in the pattern of regional sustainability at regional and local scales. Given the spatial distribution of municipalities among the five clusters, we can speculate the relationship between the rate of economic development and regional sustainability.

\section{References}

[1] Asian Development Bank, Integrated Economic and Environmental Planning at the Sub-national Level in Asia, ADB, Manilla, 2001.

[2] The World Commission on Environment and Development (WCED), Our Common Future, Oxford University Press, Oxford, 1987.

[3] Dale, A., As the edge: Sustainable development in the 21st century, Vancouver: UBC I'ress, 2001.

[4] Hanna, K.S., Planning for sustainability - experiences in two contrasting communities, Journal of American Planner Association, 71(1): 27-40, 2005 .

[5] Robinson, J., Francis, G., Legge, R. and Lerner, S., Defining a sustainable society: Values, principles and definitions, Alternatives, 17: 36-46, 1990.

[6] Andrew, F. and Manuel, W., Land use modelling at the regional scale: an input to rural sustainability indicators for Central America, Agriculture, Ecosystems and Environment, 85(1-3): 249-268, 2001.

[7] Maclaren, V.W., Urban sustainability reporting, Journal of American Planner Association, 62(2): 184-202, 1996.

[8] Ko-Wan Tsou, Yu-Ting Hung and Yao-Lin Chang, Spatial analysis of urban sustainability, Compact Cities: Sustainable Urban Forms for Developing Countries, Mike Jenks and Rod Burgess (eds), Spon Press, London, pp. 321-330, 2000.

[9] Herrera-Ulloa, Á. F., Charles, A. T., Lluch-Cola, S. E., Ramirez-Aguirre, H., Hernández-Vázquez, S. and Ortega-Rubio, A., A regional-scale sustainable development index: the case of Baja California Sur, Mexico, International Journal for Sustainable Development \& World Ecology, 10(4): 353-360, 2003.

[10] Lewis, G. M. and Brabec, E., Regional land pattern assessment: development of a resource efficiency measurement method, Landscape and Urban Planning, 72(4): 281-296, 2005.

[11] Bühler-Natour, C. and Herzog, F., Criteria for sustainability and their application at a regional level: the case of clearing islands in the Dübener Heide nature park (Eastern Germany), Landscape and Urban Planning, 46(1-3): 51-62, 1999.

[12] Ward, J. H., Hierarchical grouping to optimise an objective function, Journal of the American Statistical Association, 58: 236-244, 1963. 